\title{
LESSON 109
}

\section{Invoices}

An invoice is the document which is sent to charge for goods being bought. The style varies from firm to firm and you can expect to meet several types. Basically, an invoice is a form to be filled in and you must use your common sense to see that the correct items go in the correct places. The Value Added Tax Regulations state what information must be shown on an invoice.

On a sheet of $A 5$ paper $(210 \times 148 \mathrm{~mm})$ rule up this outline using the measurements given. If you place a sheet of Bank typing paper over your ruled up framework you will be able to see the ruled lines underneath and so use the invoice you have ruled up for the exercises which follow. Keep the framework: you will need it later.

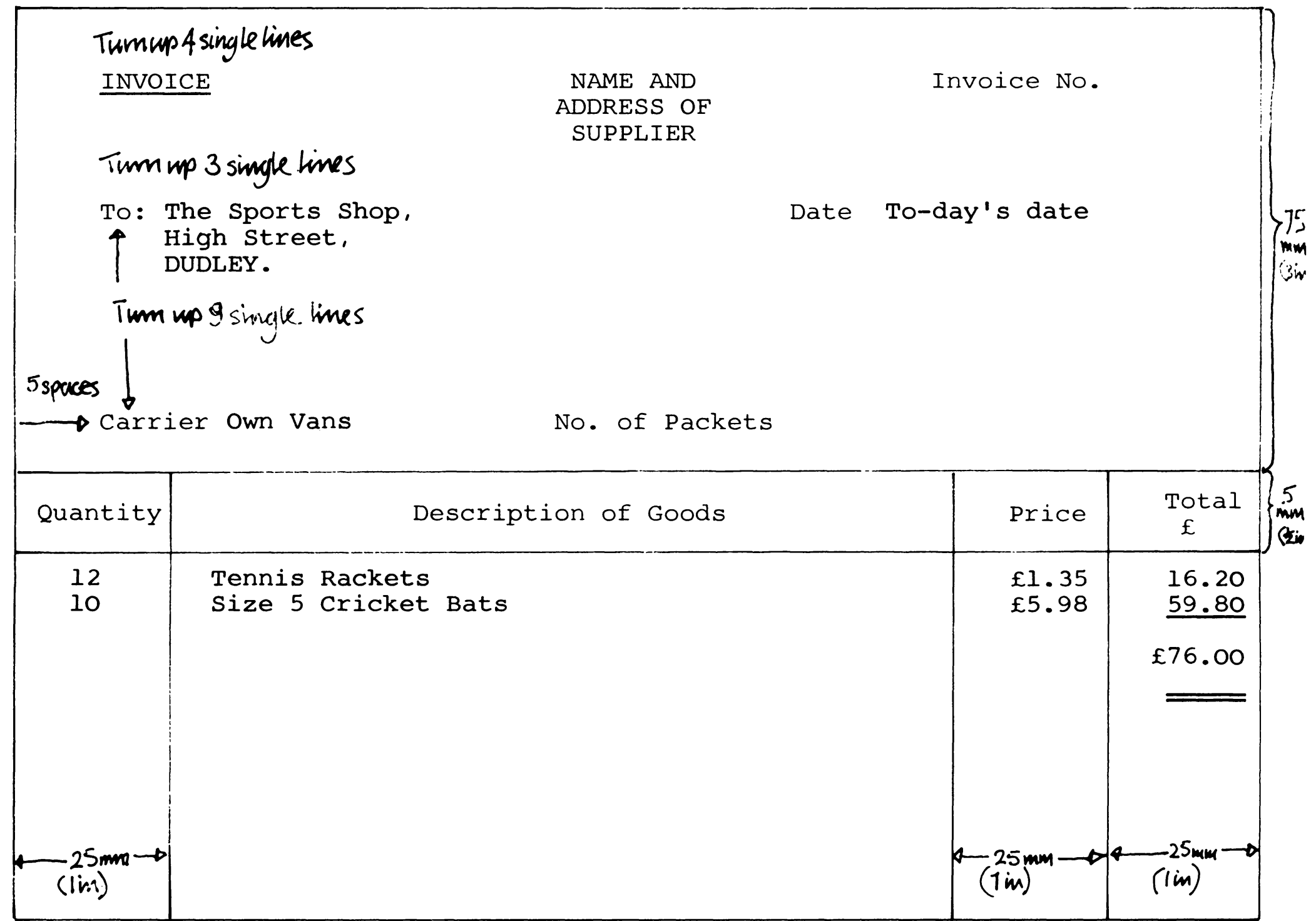

Type in the headings given so that you will see them through your top sheet.

Take your ruled up form out of the machine and use it as a backing sheet. Where it says

'Name and Address of Supplier', type J. Webster Limited, The Green, Walsall. Fill in the rest of the information as shown. Look up typing of columns of money in Lesson 105.

UNIT 28

LESSON 109 